\title{
Novel Screen-Printed All-Solid-State Copper(II)-Selective Electrode for Mobile Environmental Analysis
}

\author{
Johannes Schwarz ${ }^{1 *}$, Kathrin Trommer ${ }^{1}$, Michael Mertig',2 \\ ${ }^{1}$ Kurt-Schwabe Institut für Mess- und Sensortechnik e.V. Meinsberg, Waldheim, Germany \\ ${ }^{2}$ Institut für Physikalische Chemie, Technische Universität Dresden, Dresden, Germany \\ Email: "schwarz@ksi-meinsberg.de
}

Received 8 March 2016; accepted 27 June 2016; published 30 June 2016

Copyright (C) 2016 by authors and Scientific Research Publishing Inc.

This work is licensed under the Creative Commons Attribution-NonCommercial International License (CC BY-NC).

http://creativecommons.org/licenses/by-nc/4.0/

(c) (i) (8) Open Access

\section{Abstract}

Based on poly(vinyl chloride) membranes, a novel miniaturized screen-printed all-solid-state copper(II)-selective electrode has been developed for applications in environmental monitoring. Performance and applicability of the ion-selective electrode (ISE) have been proved by potentiometric investigations. Conducting polymers were used as intermediate layers and as solid contacts between the ion-selective membrane and the graphite transducer. The ion-complexing reagent 2-mercapto-benzoxazole was incorporated into poly(vinyl chloride) membranes. In the concentration range $10^{-6}-10^{-2} \mathrm{~mol} / \mathrm{L}$, the ISE exhibited a linear Nernstian potential response to copper(II) with an average slope value of $28 \mathrm{mV} /$ decade. The detection limit was $3 \times 10^{-7} \mathrm{~mol} / \mathrm{L}$. The electrode exhibits a short response time $(<10 \mathrm{~s})$ and can be used in the range of $\mathrm{pH}=3-7$. Selectivity coefficents against certain interfering ions are investigated. The life time of the electrode under laboratory conditions was approximately 12-month. The electrode was applied in the investigation of different aqueous environmental samples and the electrode characteristics were described. The copper(II) ASS electrode has also successfully been used in potentiometric, complexometric titrations with ethylenediaminetetraacetic acid.

\section{Keywords}

All-Solid-State Copper(II)-Selective Electrode, Conducting Polymers, Potentiometric Titration, Environmental Samples

\footnotetext{
${ }^{*}$ Corresponding author.
}

How to cite this paper: Schwarz, J., Trommer, K. and Mertig, M. (2016) Novel Screen-Printed All-Solid-State Copper(II)-Selective Electrode for Mobile Environmental Analysis. American Journal of Analytical Chemistry, 7, 525-532. 


\section{Introduction}

Contamination of ecosystems by heavy metals is of worldwide concern and represents a major problem in environmental pollution of today. Heavy metals are non-biodegradable and can accumulate in human organism. Copper is one of the most widely distributed and essential trace elements. It is of great importance for industrial applications and plays a central role in many biochemical processes. Its determination in various media is, therefore, of great interest. According to the German Drinking Water Act, the concentration of copper in drinking water has to be lower than $2 \mathrm{mg} / \mathrm{L}$ [1]. According to the United States Environmental Agency (EPA) and the World Health Organization (WHO), the maximum containment level (MCL) of copper is even lower: $1.3 \mathrm{mg} / \mathrm{L}$ [2] [3].

Many instrumental analytical methods such as atomic absorption spectrometry (AAS), inductively-coupledplasma optical emission spectrometry (ICP-OES) and inductively-coupled-plasma mass spectrometry (ICP-MS) are used routinely for copper analysis [4]-[6]. These laboratory-based methods have good precision, high sensitivity and low detection limits. Disadvantages of these methods are complex analytical operations as well as the need of qualified personnel and high cost equipment. They are also not suitable for field analysis.

Therefore, new analytical tools are required for economical real-time monitoring of environmental pollutants. During the last years, there has been an increasing demand and a high interest for miniaturized electrochemical devices for field investigations of heavy metals. Due to their portability, low cost, compactness, simplicity, easyto-use capability and robustness, electrochemical devices are promising alternatives compared to costly instrumental laboratory equipment [7]-[12]. The search for rapid, sensitive, simple, easy-to-handle and robust analyzers is still going on.

Ion-selective electrodes (ISEs) are a class of electrochemical sensors with increasing importance for on-site analysis of environmentally relevant ions. Potentiometric ion detection with ion-selective all-solid-state (ASS) electrodes has been widely developed in recent years and will be broadly applicable due to their simplicity and fast analysis. Potentiometric detection requires minimum sample pretreatment and preparation and has great potential for field analysis. In literature, the use of different ion-complexing compounds like calixarenes, Schiff's bases and thiocrown ethers is described for potentiometric copper(II) detection applying ISEs of different construction forms [13]-[25].

There are recent reports on ASS copper(II) electrodes [26]-[29]. These electrodes are mainly based on graphite pastes and expensive nanomaterials. Furthermore, the use of new synthesized ionophores is often required which results in time-consuming electrode preparation steps.

Conducting polymers (CPs) have been used as solid contact materials and intermediate layers in ASS ion-selective electrodes [30]-[36]. They are of interest because of their mixed ionic and electronic conductivity which allows a definite transfer of ion to electrical charge without using an internal liquid electrolyte. The incorporation of conducting polymers as solid contact offers new possibilities for simple and reproducible electrode construction. The internal electrolyte can therefore be replaced.

Screen-printing is a well-established technique for manufacturing of portable and disposable electrochemical electrodes. It allows the design of electrodes with small dimensions, good reproducibility and variable electrode arrangements [9] [37].

Here we report on the design, preparation, potentiometric characterization and analytical application of screenprinted, solid-contacted ASS copper(II)-selective electrodes consisting of different functional polymeric layers. As neutral carrier and chelating agent, 2-mercapto-benzoxazole (2-MBA) has been used for the first time in ASS ion-selective electrodes. 2-MBA forms stable complexes with copper(II) ions [38].

\section{Experimental}

\subsection{Reagents}

All reagents were analytical grade and used without any further purification. Solutions were prepared with deionized water. All inorganic salts used were purchased from Sigma-Aldrich Co. LCC.. Sample solutions of different ion concentration were prepared by diluting the stock solutions. Graphite and silver pastes used for screen-printed electrodes were obtained from DuPont de Nemours (Germany) GmbH. High molecular weight poly (vinyl chloride) (PVC), ortho-nitrophenyl octyl ether (o-NPOE), pyrrole, poly (3,4-ethylenedioxythiophene)poly(styrene-sulfonate) (PEDOT:PSS), tetrahydrofuran (THF), 2-MBA and ethylenediaminetetraacetic acid (EDTA) were purchased from Sigma-Aldrich Co. LCC. and used as received. 


\subsection{Apparatus and Electrodes}

Potentiometric measurements were carried out at room temperature, using the $\mathrm{pH} / \mathrm{ion}$ analyzers $\mathrm{pMX} 3000$ (WTW Weilheim, Germany) and LM 2000 (Sensortechnik Meinsberg GmbH, Germany). Ag/AgCl reference electrodes with aqueous saturated $\mathrm{KCl}$ as the electrolyte solution have been used.

A half-automatic screen printer (EKRA, FEI Germany) has been used to manufacture the screen-printed ASS electrodes.

Atomic adsorption spectrometry (novAA ${ }^{\circledR}$, Analytik Jena, Germany) was used as reference method.

\section{Electrode Preparation}

Copper(II)-selective electrodes were fabricated with different functional layers on screen-printed graphite electrodes based on $\mathrm{Al}_{2} \mathrm{O}_{3}$-ceramic substrates. The manufacture of the electrodes consists of 3 steps:

- Screen-printing of graphite on a ceramic substrate (layer 1 ),

- Application of CP (layer 2),

- Drop-casting of ion-selective membrane cocktails (layer 3).

Reproducible layer configurations were obtained. Commercially available graphite ink is screen-printed on ceramic substrates within an area of $5 \mathrm{~mm} \times 30 \mathrm{~mm}$. The thickness of the graphite layer is $\sim 500 \mu \mathrm{m}$. The graphite discs have diameters of $2.5 \mathrm{~mm}$. Polypyrrole (PPy) was prepared by in-situ electropolymerization of 0.1 $\mathrm{mol} / \mathrm{L}$ pyrrole in KCl-containing solution. PEDOT:PSS was applied by drop casting of an aqueous solution of the polymer directly onto the graphite layer. Both polymers form stable layers and show good adhesion to the graphite substrates. After applying the $\mathrm{CP}$ on the graphite surface, the electrodes were rinsed with $\mathrm{H}_{2} \mathrm{O}$ and air dried overnight. The thickness of the polymer layer is between $5 \mu \mathrm{m}$ and $10 \mu \mathrm{m}$.

The mixture of the membrane components was dissolved in $2 \mathrm{ml}$ THF and allowed to evaporate at room temperature till a viscous concentrate was obtained. After the deposition of the CPs, the ion-selective cocktail was drop casted by pipetting about $5 \mu \mathrm{l}$ onto the CP. The thickness of the resulting membrane is about $100 \mu \mathrm{m}$. The composition of the ion-selective membrane components has been optimized. Best results with average slopes of $>28 \mathrm{mV} /$ decade were obtained using the following membrane composition:

- PVC (32 wt.\%),

- 2-nitrophenyl octyl ether (65 wt.\%),

- 2-MBA (3 wt.\%).

Before the first measurement, the electrodes were conditioned in $10^{-3} \mathrm{~mol} / \mathrm{L}$ copper(II) salt solutions for at least 5 hours.

In Figure 1, the chemical structure of the 2-MBA is shown. Figure 2 shows a schematic representation of the ASS electrodes. A photograph of the ASS electrode is shown in Figure 3.<smiles>Sc1nc2ccccc2o1</smiles>

Figure 1. Chemical structure of the neutral ion-carrier 2-mercapto-benzoxazole (2-MBA).

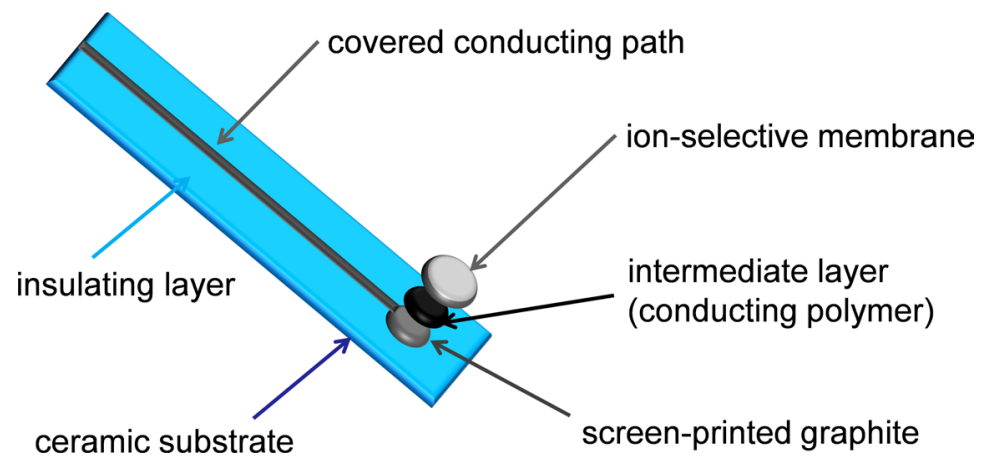

Figure 2. Schematic representation of the ASS electrode. 


\section{Result and Discussion}

\subsection{Potentiometric Investigations}

The PVC-based membrane electrodes, containing 2-MBA as neutral ion carrier, generated stable responses in Cu$\mathrm{SO}_{4}$ solutions. The dynamic response behaviour of a PEDOT: PSS-modified ASS electrode and the corresponding calibration plot are shown in Figure 4. The linear dynamic range extends from $10^{-6} \mathrm{~mol} / \mathrm{L}$ to $10^{-1} \mathrm{~mol} / \mathrm{L}$.

To evaluate the high reversibility and the fast response of the electrode, high-to-low repetitive sample concentrations were tested as shown in Figure 5. The response behaviour confirms the reversibility of the measured

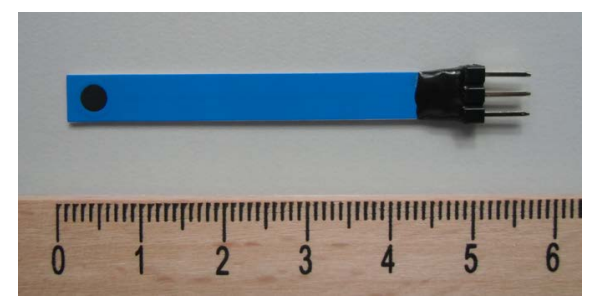

Figure 3. Photograph of a screen-printed ASS ion-selective electrode.
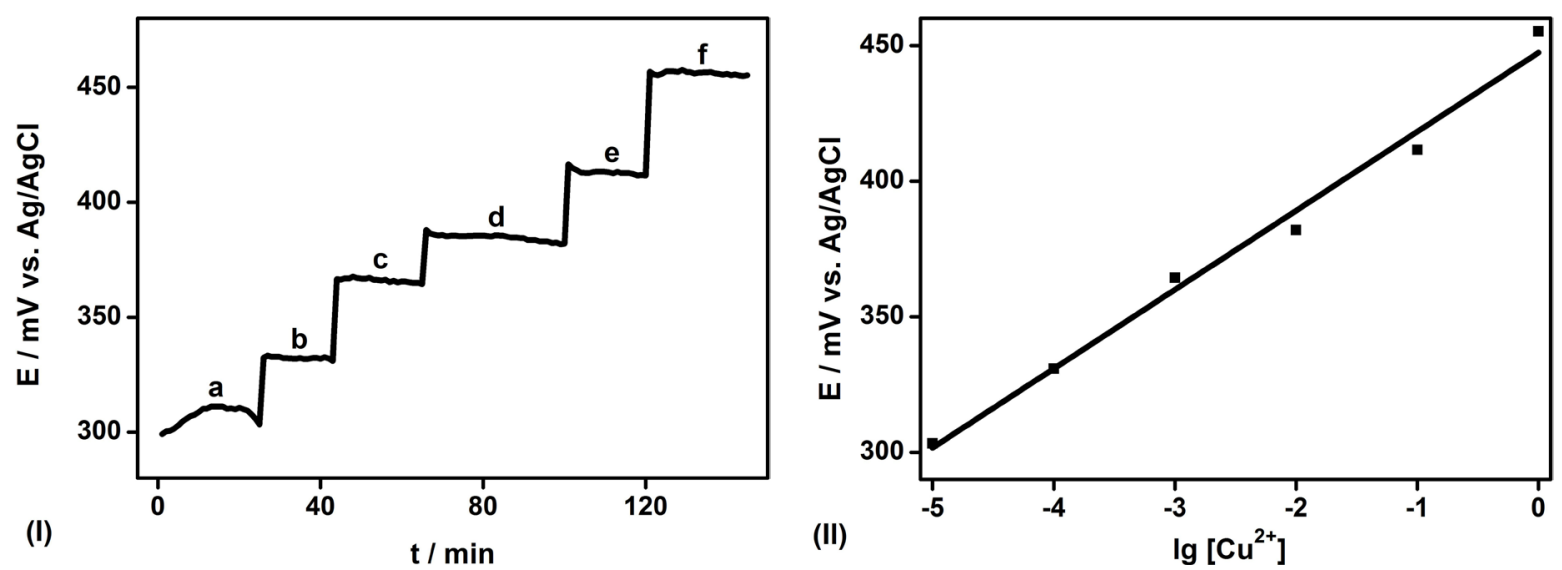

Figure 4. Dynamic potentiometric response behaviour (I) and calibration plot (II) of a PEDOT:PSS-modified ASS copper(II)-selective electrode. $\mathrm{CuSO}_{4}$ concentrations—a: $10^{-5} \mathrm{~mol} / \mathrm{L}, \mathrm{b}: 10^{-4} \mathrm{~mol} / \mathrm{L}, \mathrm{c}: 10^{-3} \mathrm{~mol} / \mathrm{L}, \mathrm{d}: 10^{-2} \mathrm{~mol} / \mathrm{L}$, e: $10^{-1} \mathrm{~mol} / \mathrm{L}$, f: $1 \mathrm{~mol} / \mathrm{L}$.

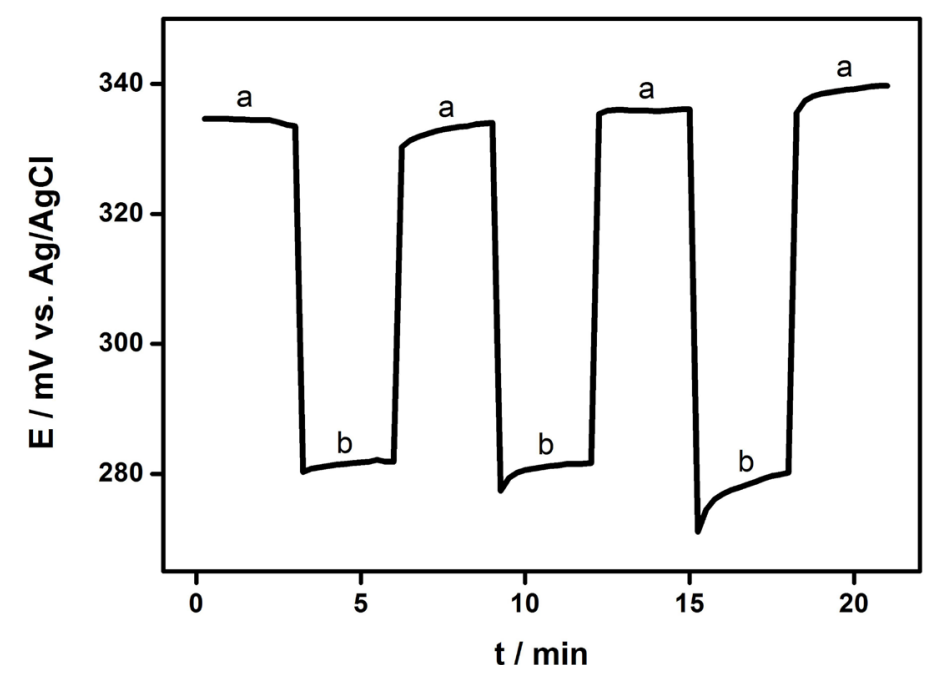

Figure 5. Dynamic response characteristics of a PEDOT: PSS-modified ASS copper(II)-selective electrode for several highto-low and low-to-high concentration cycles. $\mathrm{CuSO}_{4}$ concentrations: a: $10^{-2} \mathrm{~mol} / \mathrm{L}, \mathrm{b}: 10^{-4} \mathrm{~mol} / \mathrm{L}$. 
potentials and the fast response. The response time is $<10 \mathrm{~s}$. The calculated slope is on average $28 \mathrm{mV} / \mathrm{decade}$. The value of the regression coefficient is $\mathrm{R}^{2}=0.99$. The relative standard deviations of the potentials for $10^{-4}$ $\mathrm{mol} / \mathrm{L}$ and $10^{-3} \mathrm{~mol} / \mathrm{L}$ copper(II) salt solutions are in both cases less than $4 \%$ of 10 replicate measurements indicating good reproducibility of measurements. The working $\mathrm{pH}$-range of the electrode is between 3 and 7 and remained constant in this range. Over 12 month the electrodes showed no significant divergence in slope potential and response time. During non-usage, the electrodes were stored in air and before use they were conditioned by dipping into $10^{-3} \mathrm{~mol} / \mathrm{L}$ copper(II) salt solutions for $2-3$ hours. Consequently, the electrodes generate stable potentials when in contact with copper(II) containing solutions.

The potentiometric selectivity coefficients $K^{\text {pot }}$ have been evaluated after the separate solution method. The resulting selectivity-coefficients are given in Table 1, indicating that the proposed electrodes are selective towards the tested interfering ions.

The advantages of the new electrode, compared to other known ISEs, are the short response time, as well as a reasonable long-term stability with life times of about one year [13] [17] [20]. Due to the thin functional layer configuration, only few chemicals and materials in relatively small amounts are needed for a reproducible electrode fabrication. This allows the fabrication of low-cost electrodes in large quantities. All used chemicals, including the ion-complexing compound, are commercially available. Therefore, no time-consuming synthesis steps are necessary as described for most solid-contacted copper(II)-selective electrodes [21]-[23]. The use of screen-printing technology for the manufacture of the graphite transducers is also advantageous with regard to a possible mass production compared to devices produced by conventional methods.

\subsection{Analytical Applications}

The disposable ISEs were successfully applied as indicator electrodes in combination with $\mathrm{Ag} / \mathrm{AgCl}$-reference electrodes for complexometric titrations of copper(II) ions with EDTA solutions as titrant in standard and in spiked environmental samples. The results show that the amount of copper(II) ions can be accurately determined by potentiometric titrations using the electrodes described here. The titration plots including the first derivatives with respect to the added volume of the EDTA solution are shown in Figure 6 (standard solution) and Figure 7 (spiked river sample). PPy-modified ASS electrodes are used. The inflection point on the graph agreed well with the calculated equivalent point. The samples were prepared as follows: $40 \mathrm{ml}$ solutions of copper(II) $\left(10^{-3} \mathrm{~mol} / \mathrm{L}\right)$ (Figure 6) and $50 \mathrm{ml}$ of a spiked real water sample from the Zschopau River, Germany (Figure 7) were titrated with $10^{-2} \mathrm{~mol} / \mathrm{L}$ EDTA solution. The $\mathrm{pH}$ was adjusted to $\mathrm{pH}$ 5. Comparative analyses by colorimetric titrations were carried out using the color indicators 1-(2-Pyridylazo)-2-naphthole and 4-(2-Pyridylazo) resorcinole and by AAS as a routinely used copper detection method. The results of all three methods agree well.

The titration curves are characterized by sharp equivalent points. The copper(II) content can be analyzed with high accuracy in spiked and standard samples. The potential jump near the equivalent point is nearly $50 \mathrm{mV}$. The copper(II) content in environmental samples can be evaluated with high precision as has been demonstrated in potentiometric titrations using the novel electrode. The good accordance with the colorimetric titration must be emphasized and proves the practical utility and applicability of the novel copper(II) ASS electrode.

Environmental samples spiked with defined amounts of copper(II) have been analyzed by potentiometry using the novel electrodes and compared with AAS. The results are shown in Table 2.

\section{Conclusion}

A novel liquid-free copper(II)-selective electrode was developed and tested in standard and real samples. The electrode is based on an intermediate layer of conducting polymer deposited between the graphite substrate and the ion selective membrane. The solid contact realized by conducting polymer ensures stable and reproducible

\begin{tabular}{|c|c|}
\hline Interfering ion & $\lg K^{\mathrm{pot}}{ }_{\mathrm{MI}}$ \\
\hline $\mathrm{Cd}^{2+}$ & -2.6 \\
\hline $\mathrm{Ca}^{2+}$ & -3.4 \\
\hline $\mathrm{Mg}^{2+}$ & -4.5 \\
\hline $\mathrm{Pb}^{2+}$ & -2.4 \\
\hline
\end{tabular}



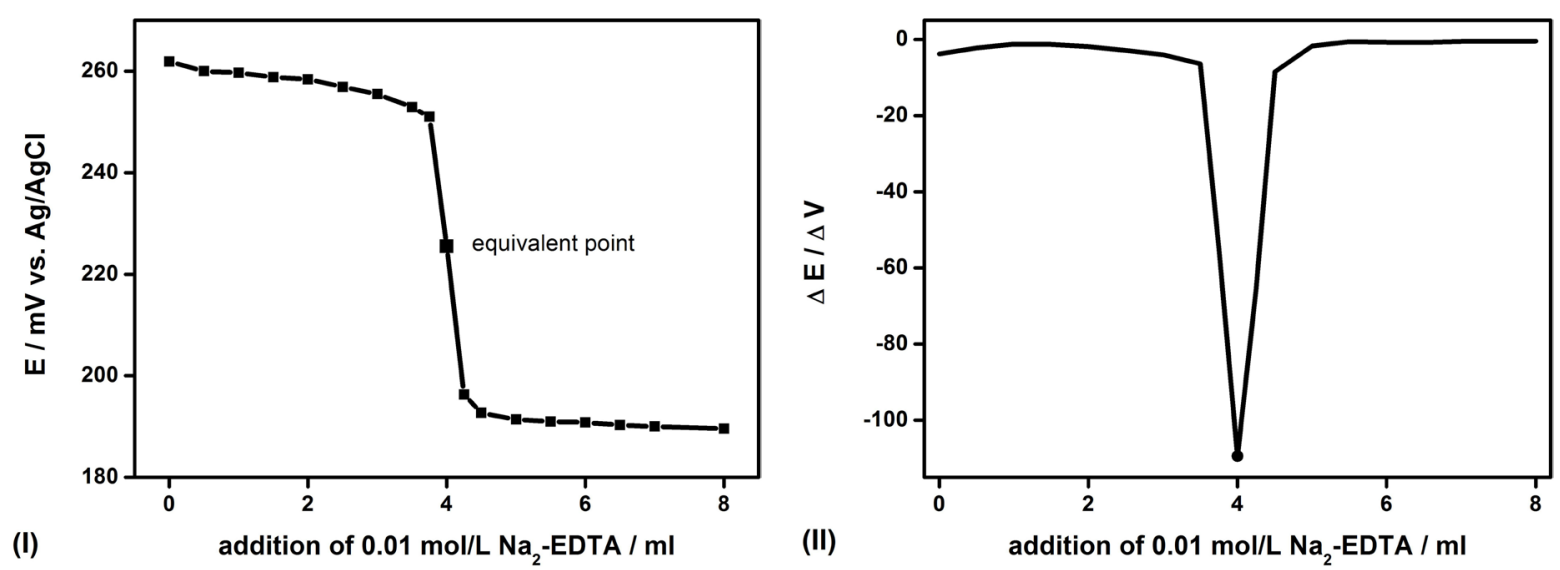

Figure 6. Potentiometric titration curve of copper(II) with EDTA using a PPy-modified ASS electrode. (I) Titration plot. (II) First derivative of the potential with respect to the added volume of the EDTA solution $(\Delta \mathrm{E} / \Delta \mathrm{V})$. Sample concentration: $10^{-3}$ $\mathrm{mol} / \mathrm{L} \mathrm{Cu}\left(\mathrm{NO}_{3}\right)_{2}$.
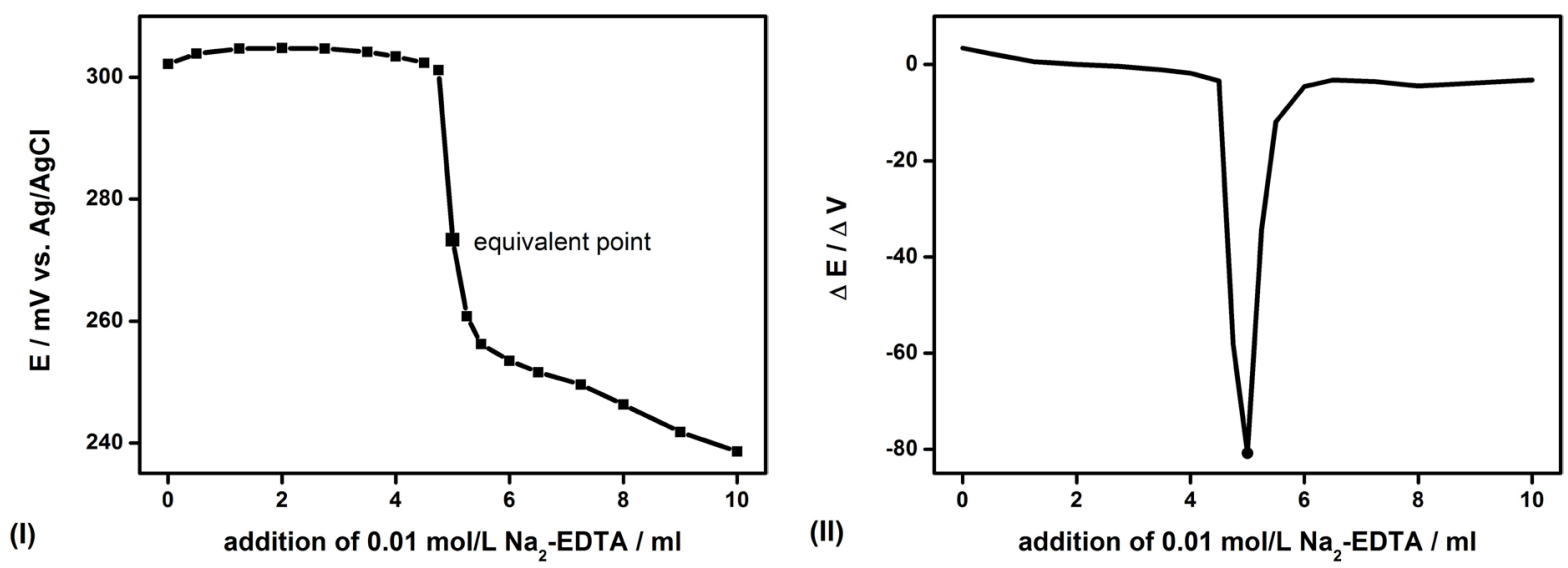

Figure 7. Potentiometric titration curve of copper(II) with EDTA using a PPy-modified ASS electrode. (I) Titration plot. (II) First derivative of the potential with respect to the added volume of the EDTA solution $(\Delta \mathrm{E} / \Delta \mathrm{V})$. Sample: spiked river water (Zschopau River, Germany).

Table 2. Determination of copper(II) ions in real water samples.

\begin{tabular}{cccc}
\hline \multirow{2}{*}{ Spiked real samples } & \multicolumn{3}{c}{ Copper(II) concentration } \\
\cline { 2 - 4 } & of spiked sample $[\mathbf{m g} / \mathbf{L}]$ & $\begin{array}{c}\text { determined by } \mathbf{I S E} \text { [mg/L] } \\
\text { determined by AAS [mg/L] }\end{array}$ & 5.8 \\
\hline River water (Zschopau, Germany) & 6.4 & 7.7 & 57.1 \\
Sea water (Baltic sea, Kolobrzeg, Poland) & 63.5 & 66.1 & 53.1 \\
River water (Rhein, Germany) & 63.5 & 62.7 & 53.9 \\
\hline
\end{tabular}

potentials. Thus, the integration of different functional polymer layers on screen-printed graphite substrates enables reproducible electrode constructs. The developed ASS copper(II)-selective electrode has a simple and stable design, can be simply prepared, provides easy handling and exhibits a long life-time. The developed electrode has good operating characteristics (sensitivity, response time, detection limit, linear range, selectivity) and high mechanical stability. Successful applications and good performance have been shown by complexometric titrations and by direct potentiometric analysis. The results confirm the analytical utility and applicability of the developed electrodes. The electrode can be successfully employed for copper(II) detection in water samples. It requires no extensive, cost intensive equipment or time consuming sample preparation, and it allows a real-time in-situ monitoring of copper(II). The novel electrode shows competitive characteristics to commercially availa- 
ble electrodes enabling sensitive mobile and decentralized copper(II) analysis. The presented screen-printed electrodes are small and easy to handle, and thus, attractive for field studies and environmental monitoring.

\section{Acknowledgements}

The authors gratefully thank the Bundesministerium für Bildung und Forschung in the context with the project BioNEWS (project number 03WKCL03G) for financial support. We also thank F. Gerlach for preparing the screen-printed electrodes and for helpful discussions in optimizing electrode layout and arrangement.

\section{References}

[1] TrinkwV (2001) Deutsche Trinkwasserverordnung.

[2] National Primary Drinking Water Standards, Water Research Center. www.water-research.net/standards.htm

[3] US Environmental Protection Agency (EPA) (2003) National Primary Drinking Water Standards. www.epa.gov/safewater

[4] Gong, R., Zhang, D., Zhong, K., Feng, M. and Liu, X. (2008) Determination of Trace Copper in Water Samples by Flame Atomic Absorption Spectrometry after Preconcentration on a Phosphoric Acid Functionaliced Cotton Chelator. Journal of the Serbian Chemical Society, 73, 249-258. http://dx.doi.org/10.2298/JSC0802249G

[5] Chwastowska, J., Skwara, W., Sterbinska, E., Dudek, J., Dubrowska, M. and Pszonicki, L. (2008) GF AAS Determination of Cadmium, Lead and Copper in Environmental Materials and Food Products after Separation on Dithizone Sorbent. Chemia Analityczna (Warsaw), 53, 887-894.

[6] Townsend, A.T., Miller, K.A., Mclean, S. and Aldrous, S. (1998) The Determination of Copper, Zinc, Cadmium and Lead in Urine by High Resolution ICP-MS. Journal of Analytical Atomic Spectrometry, 13, 1213-1219. http://dx.doi.org/10.1039/a805021j

[7] Pujol, L., Evrard, D., Groenene-Serrano, K., Freyssinier, M., Ruffien-Cizsak, A. and Gros, P. (2014) Electrochemical Sensors and Devices for Heavy Metals Assay in Water: The French Groups Contribution. Frontiers in Electrochemistry, 19, 1-14. http://dx.doi.org/10.3389/fchem.2014.00019

[8] Bobacka, J., Ivaska, A. and Lewenstam, A. (2008) Potentiometric Ion Sensors. Chemical Reviews, 108, 329-351. http://dx.doi.org/10.1021/cr068100w

[9] Tymecki, L., Glab, S. and Koncki, R. (2006) Miniaturized, Planar Ion-Selective Electrodes Fabricated by Means of Thick-Film Technology. Sensors, 6, 390-396. http://dx.doi.org/10.3390/s6040390

[10] Honeychurch, K.C. (2012) Screen-Printed Electrochemical Sensors and Biosensors for Monitoring Metal Pollutants. Insciences Journal, 2, 1-51.

[11] Hayat, A. and Marty, J.-L. (2014) Disposable Screen Printed Electrochemical Sensors: Tools for Environmental Monitoring. Sensors, 14, 10432-10453. http://dx.doi.org/10.3390/s140610432

[12] Renedo, O.D., Alonso-Lomillo, M.A. and Arcos Martinez, M.J. (2007) Recent Developments in the Field of ScreenPrinted Electrodes and Their Related Applications. Talanta, 73, 202-219. http://dx.doi.org/10.1016/j.talanta.2007.03.050

[13] Emadi, D., Yaftian, M.R. and Rayati, S. (2007) N,N-bis(1-hydrooxy-2-acetonaphthone) Propylenediamine: Synthesis, Extractive Properties and Use as an Ionophore in a Cu(II)-Selective Potentiometric Sensor. Turkish Journal of Chemistry, 31, 423-433.

[14] Ansari, R., Mosayebzadeh, Z., Arvand, M. and Mohammad-Khah, A. (2013) A Potentiometric Solid State Copper Electrode Based on Nanostructure Polypyrrole Conducting Polymer Film Doped with 5-Sulfosalicyl Acid. Journal of Nanostructure in Chemistry, 3, 33-42. http://dx.doi.org/10.1186/2193-8865-3-33

[15] Ganjali, M.R., Poursaberi, T., Babaei, L.H., Rouhani, S., Yousefi, M., Kargar-Razi, M., Moghimi, A., Aghabozorg, H. and Shamsipur, M. (2001) Highly Selective and Sensitive Copper(II) Membrane Coated Graphite Electrode Based on a Recently Synthesized Schiff's Base. Analytica Chimica Acta, 440, 81-87. http://dx.doi.org/10.1016/S0003-2670(01)01051-0

[16] Mahajan, R.K. and Sood, P. (2007) Novel Copper(II)-Selective Electrode Based on 2,2':5',2”-Terthiophene in PVCMatrix. International Journal of Electrochemical Science, 2, 832-847.

[17] Ardakani, M.M., Mirhoseini, S.H. and Salavati-Niasari, M. (2006) Copper Selective Electrode Based on 1,8-bis(2-Hydroxynaphthaldiminato)3,6-Dioxaoctane. Acta Chimica Slovenica, 53, 197-303.

[18] Firooz, A.R., Mazloum, M., Safari, J. and Amini, M.K. (2002) Coated-Wire Copper(II)-Selective Electrode Based on Phenylglyoxal- $\alpha$-Monoxime Ionophore. Analytical and Bioanalytical Chemistry, 372, 718-722. http://dx.doi.org/10.1007/s00216-001-1205-7 
[19] Isa, I.M., Saidin, M.I., Ahmad, M., Hashim, N., Ghani, S.A. and Si, S.M. (2013) Development of New Copper(II) Ion-Selective Poly(vinyl chloride) Membrane Electrode Based on 2,6-Diacetylpyridine-(1R)-(-)-Fenchone Diazine Ligand. International Journal of Electrochemical Science, 8, 11175-11185.

[20] Ganjali, M.R., Ghafarloo, A., Faridbod, F. and Norouzi, P. (2012) Copper-Selective PVC Membrane Sensor. International Journal of Electrochemical Science, 7, 3706-3726.

[21] Yoshimoto, S., Mukai, H., Kitano, T. and Sohrin, Y. (2003) Copper(II)-Selective Membrane Electrode Based on Hydrotris(3-isopropylpyrazolyl)methane in a Poly(vinyl chloride) Matrix. Analytica Chimica Acta, 494, 207-213. http://dx.doi.org/10.1016/S0003-2670(03)01012-2

[22] Vlascici, D., Popa, J., Fagadar-Cosma, G., Popvici, H. and Fagadar-Cosma, E. (2013) Potentiometric Detection and Removal of Copper Using Porphyrins. Chemistry Central Journal, 7, 111-117. http://dx.doi.org/10.1186/1752-153X-7-111

[23] Norouzi, P., Ganjali, M.R., Faridbod, F. and Salavati-Nisari, M. (2006) Determination of Copper in Black, Red Pepper and the Waste Water Samples by a Highly Selective Sensitive Cu(II) Microelectrode Based on a New Hexadentates Schiff's Base. Bulletin of the Korean Chemical Society, 27, 1439-1444. http://dx.doi.org/10.5012/bkcs.2006.27.9.1439

[24] Ganjali, M.R., Emani, M. and Salavati-Niasari, M. (2002) Novel Copper(II)-Selective Sensor Based on a New Hexadentates Schiff's Base. Bulletin of the Korean Chemical Society, 23, 1393-1398.

[25] Yu, S.-Y., Li, Y.-C., Xiong, T., Yuan, Q., Liu, Y.-M., Yuan, Z.-Y. and Xiao, Y. (2014) A Ladder Conjugated Polymer Transducer for Solid-Contact $\mathrm{Cu}^{2+}$-Selective Electrodes. Chinese Chemical Letters, 25, 364-366. http://dx.doi.org/10.1016/j.cclet.2013.11.015

[26] Liang, R., Yin, T. and Qin, W. (2015) A Simple Approach for Fabricating Solid-Contact Ion-Selective Electrodes Using Nanomaterials as Transducers. Analytica Chimica Acta, 853, 291-296. http://dx.doi.org/10.1016/j.aca.2014.10.033

[27] Tutulea-Anastasiu, M.D., Wilson, D., del Valle, M., Schreiner, C.M. and Cretescu, I. (2013) A Solid-Contact Ion Selective Electrode for Copper(II) Using a Succinimide Derivative as Ionophore. Sensors, 13, 4367-4377. http://dx.doi.org/10.3390/s130404367

[28] Ganjali, M.R., Rezapour, M., Pirali-Hamedani, M. and Rashedi, H. (2015) Cu(II)-All Solid State Sensor Ion Selective Electrode (ASS-ISE) with a Nano-Molar Detection Limit and Its Use for the Analysis of Waste Water Samples. International Journal of Electrochemical Science, 10, 6924-6934.

[29] Ali, T.A., Mohamed, G.G. and Othman, A.R. (2015) Design and Construction of New Potentiometric Sensors for Determination of Copper(II) Ion Based on Copper Oxide Nanoparticles. International Journal of Electrochemical Science, 10, 8041-8057.

[30] Faridbod, F., Ganjali, M.R., Dinarvand, R. and Norouzi, P. (2008) Development in the Field of Conducting and NonConducting Polymer Based Potentiometric Membrane Sensors for Ions over the Past Decade. Sensors, 8, 2331-2412. http://dx.doi.org/10.3390/s8042331

[31] Zachara, J.E., Toczylowska, R., Prokrop, R., Zagorska, M., Dybko, A. and Wroblewski, W. (2004) Miniaturized All-Solid-State Potentiometric Ion Sensors Based on PVC-Membranes Containing Conducting Polymers. Sensors and Actuators B: Chemical, 101, 207-212. http://dx.doi.org/10.1016/j.snb.2004.02.052

[32] Bobacka, J. (2005) Conducting Polymer-Based Solid-State-Ion-Selective Electrodes. Electroanalysis, 18, 7-18. http://dx.doi.org/10.1002/elan.200503384

[33] Rahman, M.A., Kumar, P., Park, D.-S. and Shim, Y.-B. (2008) Electrochemical Sensors Based on Organic Conjugated Polymers. Sensors, 8, 118-141. http://dx.doi.org/10.3390/s8010118

[34] Ramanavicius, A., Ramanaviciene, A. and Malinauskas, A. (2006) Electrochemical Sensors Based on Conducting Polymer-Polypyrrole. Electrochimica Acta, 51, 6025-6037. http://dx.doi.org/10.1016/j.electacta.2005.11.052

[35] Gupta, N., Sharma, S. and Mir, I.A. (2006) Advances in Sensors Based on Conducting Polymers. Journal of Scientific \& Industrial Research, 65, 549-557.

[36] Kirchmeyer, S. and Reuter, K. (2005) Scientific Importance, Properties and Growing Applications of Poly(3,4-ethylenedioxythiophene). Journal of Materials Chemistry, 15, 2077-2088. http://dx.doi.org/10.1039/b417803n

[37] Menil, F., Debeda, H. and Lucat, C. (2005) Screen-Printed Thick-Films: From Materials to Functional Devices. Journal of the European Ceramic Society, 25, 2105-2113. http://dx.doi.org/10.1016/j.jeurceramsoc.2005.03.017

[38] Akhond, M., Ghaedi, M. and Tashkhourian, J. (2005) Development of a New Copper(II) Ion-Selective Poly(vinyl chloride) Membrane Electrode Based on 2-Mercaptobenzoxazole. Bulletin of the Korean Chemical Society, 26, 882886. http://dx.doi.org/10.5012/bkcs.2005.26.6.882 


\section{Submit or recommend next manuscript to SCIRP and we will provide best service for you:}

Accepting pre-submission inquiries through Email, Facebook, Linkedin, Twitter, etc A wide selection of journals (inclusive of 9 subjects, more than 200 journals)

Providing a 24-hour high-quality service

User-friendly online submission system

Fair and swift peer-review system

Efficient typesetting and proofreading procedure

Display of the result of downloads and visits, as well as the number of cited articles

Maximum dissemination of your research work

Submit your manuscript at: http://papersubmission.scirp.org/ 